\title{
Our family portrait: the church as a model of social support
}

\author{
Liza Ngenye \\ Department of Communication, George Mason University, Fairfax, VA, USA
}

\begin{abstract}
The church means many things to many people. Some would describe it as a culture, network, organization, or family. The purpose of this study is to understand of the role of the church in providing social support to individual church members and to uncover meanings prescribed by individuals about the nature of social support in the church. I analyze the context in which church practices are embedded, the processes of creating social support, and the meanings of church-related activities and gatherings that contribute to social support. The study examines how the health-related needs of church members are not only physiological but also accounted for in emotional, psychological and social terms. By using metaphor as a framework for interpretation of members' meanings, my analysis of social support is broadened to include religious contexts. This study adds to growing literature on the connection between religion, communication and health.
\end{abstract}

\section{Introduction}

The church means many things to different people in the faith community. Some would describe it as a home, culture, network, organization, or family. All these descriptive words give a glimpse of the church's role in in-

Correspondence: Liza Ngenye, Department of Communication, George Mason University, 4400 University Drive MSN 3D6, Fairfax, Virginia 22030, USA.

Tel.: 703.993.1090.

E-mail: lngenye@gmu.edu

Key words: Church; Social support; Family; Health communication.

Conflict of interest: the author declares no potential conflict of interest.

Funding: none.

Dedication: this article is dedicated to Lois Ngenye, the author's mother, whose spiritual support has been a source of inspiration.

Acknowledgements: first, the author would like to thank the journal's editor and reviewers whose feedback strengthen this paper tremendously; secondly, the research participants and congregations that made this project possible; and finally, the author would also like to thank Timothy Gibson and Gary Kreps for their guidance in research.

Received for publication: 15 August 2017.

Revision received: 23 February 2018.

Accepted for publication: 24 February 2018.

This work is licensed under a Creative Commons Attribution NonCommercial 4.0 License (CC BY-NC 4.0).

CCopyright L. Ngenye, 2018

Licensee PAGEPress, Italy

Qualitative Research in Medicine \& Healthcare 2018; 2:45-54

doi:10.4081/qrmh.2018.6996 dividual lives and how the presence and interaction with others of similar beliefs may provide a sense of belonging and support. The purpose of this study is to gain an understanding of the role of the church as social support and how it contributes to its members' emotional, psychological and social wellbeing in modern-day society.

The genesis of this project began with my interest in the relationship between the church and wellbeing. Koening $^{1}$ discovered that religion may serve as a psychological and social resource, which provides its community a sense of meaning and purpose, an optimistic and hopeful view of life, and a sense of control over circumstances. Salsman et $a l^{2}$ found a positive correlation between religion and health: the more religion or spirituality, the better the health outcome; such as emotional wellbeing and less general distress, depression, anxiety, and other distress from chronic illness. Park ${ }^{3}$ supported these findings and argued that religion may provide intrapersonal and interpersonal support to cope with significant stressors such as chronic illnesses. This study extends this insight to examine the ways in which how social support is provided by the church. In the following sections I review relevant literature on the nature of social support in religious contexts and provide a conceptual framework, and then I present findings and a discussion to interpret my data. Finally, I end with some challenges I encountered during this study and directions for future research.

\section{What's religion got to do with it?}

Research suggests positive mental health outcomes result from religious involvement. For example, multiple studies have found the church provides social capital, which contributed to emotional functioning and less depressive symptoms in the African-American community. ${ }^{4-7}$ Additionally, in India, Gupta, Avasthi, and $\mathrm{Kumar}^{8}$ found that there was a positive effect of providing religious elements 
in the treatment of depression. There are longitudinal studies that support these cross-sectional findings. ${ }^{9}$ One multigenerational study of Mexican Americans found religious attendances reduced depression ${ }^{10}$ and another 3-year study of African Americans found that those who attended religious services more than once a week reported less psychological distress and reduced risk of depressive disorders. ${ }^{11}$ Empirical research suggests three somewhat controversial conclusions: i) non-religious individuals are at a greater risk for depression; ii) religious individuals are at a lower risk for depression; and iii) participation in religious activities reduces the risk of depression. ${ }^{12}$

Blazer's empirical framework proposes a connection between religious involvement and support for emotional, psychological and social wellbeing. ${ }^{12}$ That suggests regular church attendees experience less depressive symptoms overall but that doesn't answer the question of how this phenomenon takes place. A few theories suggest concepts which explicate this phenomenon. The explanatory Religion-Health Meditational Model examines the role of specific mediators such as coping, social capital and selfefficacy towards greater mental health outcomes. ${ }^{5,13}$

The theoretical and empirical studies reviewed above refer to specific individual-level traits such as religious beliefs and religious identification as an explanation. There is, however, a gap in understanding how social interactionism, group-level dynamics such as context, social processes and organizational structures, are the basis of social support in the church. The theory of social integration posits, the size of a community, frequency of interaction, and perceived support from social communities, which affect positive wellbeing. ${ }^{14}$ The implication of social integration is that regular church attendance, religious services and activities create opportunities for the formulation of friendships between people who share similar values, interests and activities. ${ }^{9}$ Social integration, having friends in church who are available to offer advice and caution, could help individuals avoid negative experiences such as economic or legal problems by providing a sense of predictability and stability in one's life situation. ${ }^{14}$

In this article, I expand on previous research to explore how the social and organizational framework of the church is the basis of social support for individual members. However, the widely-used concepts of coping, social capital, self-efficacy and social integration will not be used, instead the theoretical focus of this study is social support.

The current conceptualization of social support is broad, for it is defined as the availability of psychological, material, and social resources from close relations such as family and friends. ${ }^{14}$ Research supports the notion that social support is more accessible in religious communities that promote compassion and kindness, especially to the underserved; many churches seek to ameliorate the effects of poverty, needs of youth and families, and provide health services. ${ }^{9}$ Social support in the church comes in various forms such as counseling, tangible aid such as goods and services, and spiritual and socio-emotional support such as prayers, visitations, comforting and companionship. ${ }^{9}$

The concept of social support has shaped the research goal of this study by focusing my attention on how exactly the church provides social support to its members, especially through the social and organizational framework of the church as the basis of social support. This perspective offers a social, contextual dimension of the supposed relationship between the church and individual members.

The first goal of this study is to understand what social support in the church means to individual members, this describes the meanings and context of social support in the church. The second goal seeks to uncover the social and organizational structures that provide social support to members, this involves the social processes in the church. This study will unpack the contextual environment of the church and the social structures of creating social support in the church among individual members (Figure 1).

The following research questions organize my inquiry:

RQ1: How is social support in the church defined?

RQ2: What are the social and organizational structures of social support in the church?

RQ3: How do the social and organizational structures provide social support in the church?

\section{My toolbox}

In the anthropologic theory in Clyde Kluckhohn's Mirror for $\mathrm{Man}^{15}$ a similar away of thinking, feeling and believing is described as a culture. Therefore, faith could

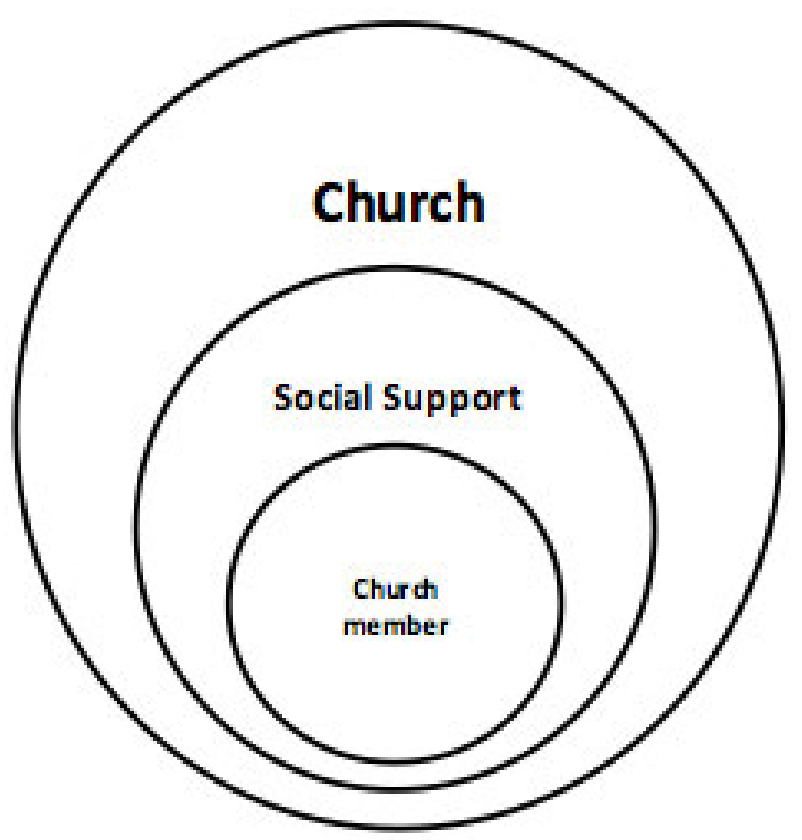

Figure 1. Conceptual framework. 
be considered a culture and the faith community would be a culture-sharing group. A ethnography is the most appropriate qualitative research approach to describe the issues, beliefs and behaviors of a culture-sharing group. ${ }^{16}$ The purpose of a ethnography is to describe and interpret a culture-sharing group and draws from research traditions of anthropology and sociology. ${ }^{16}$

The ethnography of communication offers a system of concepts that can be used to conceptualize the basic phenomena of study such as culture, which represents a group of people who share rules for using and interpreting a communication practice. As communities of people gather in communication they conduct themselves in pattern ways of speaking that identify which community they belong. ${ }^{17}$ Data gathered from an ethnography provides rich descriptions and major themes about a culture-sharing group. ${ }^{16}$

Following an interpretative research paradigm, ${ }^{18}$ I endeavor to analyze meanings made by individuals about themselves and their social life. These meanings reside in individuals and can be discovered using qualitative interviews, which are structured conversations to explore participants' experiences and beliefs, with the aim to developing an understanding of how they interpret their lifeworld. ${ }^{19}$

Drawing on these methodologies, I conducted eight interviews from March to May 2017. Using purposive sampling, the participants were recruited from a church located in Virginia and the participants ranged in age, gender and race. My interviewees were a pastor, a pastor's wife, one elder, two ministerial leaders, and four church members. The one-on-one, audio-taped interviews took 30 to 60 minutes, and one interview with two participants took two hours. All participants gave their informed context, confidentiality was maintained, and identities concealed to prevent any unforeseeable risks in participating in this study, such as the breaking of social bonds and relationships in the church. This research project received Institutional Research Board approval.

As a regular church member, the researcher had established relationships with the participants and was able to gain access and collect extensive data. Although the sample size was small, there was sufficient data gathered to identify patterns of discourse. The sample size did not hinder the goals of interpretative qualitative research, as these findings are not to be generalized to the larger population, but rather provide rich detail of a specific context. I will discuss the challenges of recruiting participants below.

The interviews covered questions concerning church life and participation. The interview script was divided to four sections: i) how they joined the church; ii) what support they received from church members; iii) experiences in church life; and iv) what church community meant to them. Church leaders were asked additional questions related to their leadership role. The interviews provided 76 double-spaced pages of transcripts. These transcripts were analyzed using open coding ${ }^{20}$ following a constructivist approach to building grounded theory. The open coding process allowed broader sense of the data developing a cohesive interpretation of the findings. The next section is a presentation of the major findings and demonstrates this commitment to robust and saturated data in the verbatim quotes from the interviews.

\section{Church life 101}

Before we move on, I will provide some background to understand the basics of the organization in many churches. Every community has a leader and in the church this leader is usually the pastor or priest. In order to the execute his or her duties, the pastor delegates many responsibilities to other leaders called elders and deacons; these individuals oversee the community and, in many churches, the community is broken down into smaller groups called ministries lead by them or other appointed leaders. This organizational structure comes from the apostle Paul's detailed description found in $1^{\text {st }}$ Timothy 3:1-13.

Church membership occurs two ways, by birth or by initiation. In many churches, church membership is not permanent but subject to certain terms and conditions such as attendance, paying of tithe, fulfilling sacraments, and maintaining good conduct; these terms are communicated during the initiation process. An interesting story of good church conduct is recorded in Acts 5:1-11, whereby a husband and wife died for noncompliance; after lying about their mismanagement of church-dedicated funds the church leaders warned the punishment was their sudden death.

Church life is formulated and maintained through social gatherings such as weekly worship services, observance of holy days, and mid-week fellowship such as bible study. There are other activities that are tailored to specific demographics such as women and men's ministries, and children's programs. The first churches were led by social activities, the record states, they continued steadfastly in the apostles'doctrine and fellows hip, in the breaking of bread, and in prayers (Acts 2:42). Church life is the center of life for many church members.

\section{We are family}

In my interviews, I wanted to understand the background of my participants; who they are, what their childhoods were like, and most importantly what family meant to them as it related to the church. In this interview with a young female graduate student, she described her childhood as it related to her relationship with the church:

My mom had gone to church with her neighbors as a child and not really with her family but her family was kind of, like they would say they were Christian but they didn't really go to church as a family and then my dad went to church with his parents, a Methodist 
Church, but they didn't really go to church with us. So, they would both say that they're Christians, but they didn't really, going to church wasn't really an important thing... my parents started dropping me off at the church on Sundays and so I would go from the time I was in $5^{\text {th }}$ grade to church alone every Sunday, my parents would drop me off and pick me up after, and we did that all the way till high school. And a couple of times I would talk to my parents about like, 'why don't you go with me?' like, 'this is something you could do too...everybody else's parents go with them like why don't you go with me?' And my parents were, my dad was kind of aversive to it, but my mom would say, 'I can't go because of your sister'...And that's ok. That's how it was for me. But I'm really glad that I got to go. And then, through growing up in college, I ended up continuing going to church and it's just been something I'm comfortable with, walking into church alone because I never had an experience really different from that until I started going with a boyfriend.

The role of parents in initiating their children to church life is the genesis of social integration. Other participants I talked to re-echoed that their parents intentionally made that decision for them, and that parental decision became so influential that they decided to continue attending church today. People come from various families and enter into a larger family in the church: this is what defines belonging to a church family. In this except a woman in her fifties describes what belonging to a church means, specifically how it allows people to offer support during trying times:

I lost my mom and I felt like I had the support of the church with their prayers, with their calls, with their cards, with praying and lifting me up and checking on me. Part of belonging to a church is having an extended family where you feel like you belong to a community of people who actually care about you and care about what happens to you. So, if something were to happen, especially in the church where I came from before my current church, I felt like that was family where if something happened or were to happen that I really needed someone or something that I could lean on my church family. I felt support, especially when my mom passed. Everyone was so caring and so helpful and wanting to do something to help make things better, or make you feel better, you just felt like you had a family to lean on, I felt the church's support most recently when my mom passed.

When individuals join the church, they are adopted by new parents. The pastor is the head of the church family. His role, as accorded by members and scripture, is that of a parent that oversees the wellbeing of the church family. One of my participants talked about her youth pastor and the role he and his wife played in her childhood:

So, Chris was not the head pastor at our church, he was the youth pastor, so he was in charge of the middle and high school students but because he was in charge of the middle and high school students. He was very specialized in working with our age group, so he knew kind of the problems that we would go through, he also knew that it wasn't going to be intellectual things that he was going to be talking about every week, it was also going to be keeping our attention, meeting us where we were as kids can change, kids can change in the course of one sermon right? (laughs). And he was the type of person that made you feel like you could ask any question and it wouldn't be wrong, it wouldn't be stupid. But, he also made you feel like you wanted to ask the types of questions that he, that only he could give you the answer to and I realize now, that any pastor could give you the answer really, but from that time he was like the authority that I saw. And April, April was supportive of not just Chris, but of everyone in the group and so if you felt like you couldn't ask Chris a question because you couldn't ask in the big group, April was someone you could go to one on one and she was just so just sweet and she made it, this interaction where there was no judgment. You could get the information you needed, or you could tell her the problems in your life and you didn't have to worry ever. It truly was that she was there to strengthen. And so, you never had to worry with these people about being torn down in anyway, which is really hard to find, there aren't very many people in the world like that and so to have that was incredible. Like I can't even describe how incredible that is...It's about I'm here for you whenever you need. And I think that's what a church should be...

Another responsibility of the pastor, as a parent, is to protect his members from possible threats that may harm their spiritual, mental and social wellbeing. I spoke to a senior elder who shared a scene when the pastor protected his members from a threat:

Unfortunately. And the church is a lot like that. You know Achans in the church, people who fornicating left and right, and that affects the entire body. And so, what are you going to do? You have brothers in the church who are predators. They just working these young ladies, they're tall, attractive, handsome and they lie to them, deceive them, get in bed with them, treat them like throw-away. And so that causes other problems. Next time she meets a guy, you know what he has got to go through because she's done with this one... and the next time he meets a girl you know...so it's a terrible cycle in the church. I remember our pastor knew a guy who had that reputation and he started coming to \#\#\#. Pastor meet him right out there, he says 'I don't want you coming to this church, I know what you do. I do not want you here.' The guy left. Now if he was serious about his life, he would have said, 'well Pastor I've changed, I'm not going to do that, I'm not going to prey upon your females in the 
church,' and he would stay. He left. So that's a shepherd who's concerned about his church, who's aware of the weaknesses of his sheep and is seeking to protect them. Not every pastor does that. Not every pastor is interested enough to be aware of the wolves that lurk out there.

In this quote, we see the metaphor of shepherding to describe the protective nature of a religious leader and his responsibility to secure his congregation. As a shepherd, a pastor needs to be aware of threats that may undermine the physical, emotional and spiritual wellbeing of his members, but that can only be known if the pastor is aware of his members' weaknesses. In this instance, the pastor was leading a church of many affluent single women who were looking for life partners, the pastor had to protect their vulnerability by ensuring safe partnerships and keep out those who would deter their ability to discern healthy relationships.

It is not possible for the pastor to successfully execute his role as a parent and shepherd if there is a lack of awareness of his children's needs. Although church leaders may be responsive, wanting to take proactive measures to deal with issues, they are inhibited by unawareness. Subsequently, this causes many people to leave the church. The church that I investigated was fairly large, almost thousand registered members, and the pastor I spoke to had this to say:

Researcher: Sadly, many people don 't get help, it's just the nature of the church, maybe they fall through the cracks, we don't know what they need, they just disappear from the system. Have you witnessed someone disappear from our system, you don't know where they went, what happened to them?

Pastor: Yeah it happens all the times. Sometimes people are very secretive of the issues they're facing, and rather than share it to anyone, open up to anyone, they just quietly leave the scene and then all of a sudden you discover that they are no longer around. Because, unless the need is expressed, the desire for counseling for help is expressed, sometimes you can't just read body language or facial language to determine that this person has such and such needs. So, these individuals who are either very private or very secretive, sometimes they do fall through the cracks because no one really knows the kind of trauma they're experiencing, so they don't provide them with help that could be forthcoming.

Researcher: How does that make you feel as a pastor?

Pastor: I feel badly because spirituality is not all that people need. We are created as harmonious creatures: mental, physical, social, spiritual and all of the dimensions of the human being must be met, must be satisfied. If one is overly spiritual, and he's having mental problems or emotional problems or social problems, then that person becomes unbalanced so it makes me feel sad when I recognize that balance is not being created or people are not helped to live a balanced life and the church doesn't provide for all the dimensions of the human being.

Similarly, the elder also agreed. He gave an explanation of why it was impractical for one individual to cater to all the needs of a thousand members:

One person I can think of who had...became disenchanted for some reason, with the church...or maybe going through something...I can't remember exactly what was his issue at this point. But he did not, he stopped coming for a while...And finally, I just... a guy who I knew grew up in the church, doing pretty well. I just happened to call him or see him and said, 'How are you doing?' He said, 'Well...I'm getting ready to leave the church.' I said, 'the organized church? why?' He said, 'well I've been gone for the past... the pastor hasn't called me, or come visited me." I said ok. And actually, I went to the pastor and said, 'look there's this person who has not...' He (the pastor) said, '\#\#\# look, I got a church of a thousand people. Call the brother. I can be going around holding people's hands. So, if you are committed, then be committed.' But...you know...so ... with that many people... And this is why we have the church structure organized so that we have 22 elders, each elder has a certain portion of the congregation assigned to them, supposed to call and be in contact with, so that if those people are missed, it's your responsibility to get them. And... you know...so unless...so the pastor is not the one who supposed to contact everybody and know what everybody is doing. The other thing you have is, there are people who have problems who never call the church. So, someone says, my wife says to me, 'this lady, you know, she was sick, she was off.' I said 'did she tell anybody?'She says, 'no, she's very private.'I said, 'Oh. How are people supposed to know?' So, there are people like that in the church, who will not share their issues. They may have cancer, they may have loss of job, but they don't share... and they say nobody called me, nobody comforted me. Well nobody knew. Or they'll say pray for me but don't tell the elders, don't tell the deacons. Well what can we do with that, when you have that?

The identification of needs is another challenge to church leaders. Many pastors are not trained in mental health counseling as part of pastoral training, the elder I spoke to confirmed this. I asked the elder what process or method they used to identify the needs of their members. The process he described is the discernment of spiritual needs from psychological needs, that closely resembles a type of filtration. In this process, the church leader assesses if the needs are spiritual, if so they offer spiritual counsel; if the issues involve other emotional struggles they attempt offer advice. This elder provided a scenario to illustrate this process: 
Elder: Because you may have a pastor who has none of that training. So. the pastors come...they all say they're been trained in theology. But it's based on their interest, that they would be involved in mental health...counseling. Pastors don't come with counseling skills automatically. So, unless they are willing to go that route. You know Pastor \#\#\# was trained in theology and administration. And he also on his own did the counseling, but not all pastors have that training or desire it. It's not a pre-requisite for pastoring (laughs).

Researcher: So, what happens then? You just learn on the job or what?

Elder: You learn on the job because you get to know, they are people you love and they come to you with problems and you really sit and say I really don't know how to help this person, I need to get some help and so on their own basis, based on the pressure of situations where they're not helping people with their own problems they go out and get that training. But unless they have that sense of responsibility...they say go to this person, go to that person ... they themselves never get trained. So, you have all kinds of pastors, but counseling is not a requisite for getting a pastoral call.

Researcher: I think you mentioned instances where you've had to call professionals, and earlier you said a lot of these mental issues come from spiritual problems. Is there a clear distinction between, ok this is a spiritual issue we just need, you know spiritual guidance, versus you know this has gone this direction maybe we need a professional? Is there some clarity as to where one starts and where one ends...?

Elder: When you start with, 'What's the problem? Where hurts? Where are the pain points?'From there you begin to glean, oh yeah, I can help or I can't help because this is deeper than I can do. I had one couple came and they both came they wanted counseling and the symptoms that was manifested there was no way to get out of it. He was unemployed and was in a situation where he was almost unemployable because of lack of skills or interest in doing things. And so, I know for a female having a man who you know you need to support and having kids, I mean, 'You are the man you gotta get a job. You gotta get one quickly! You're not getting money to support your family.' That is the issue. So, we can go wherever but until that thing is removed... You know she would appreciate if you could go work at McDonalds but you're not doing that... that's not my thing. So, she came back and she says, 'Look I need to talk to you.' I said fine and we made an appointment and she said, I'm not interested in a relationship anymore. I said is there anything I can say? She said no. So, I said if we sit here and talk for the next half hour we're wasting time? She says yes. Ok well, I don't want to waste your time or mine (laughs) and that was the end of that...So, you have, I mean...human beings get untangled in issues. We create so many problems...

Even if church leaders were aware of needs, the last hurdle they faced was unwillingness or lack of commitment of individuals to their own self-improvement. Unwillingness was described as the last barrier preventing the leader's ability to sufficiently cater to the needs of members in the church. The elder continued:

Relationships take work and unless you've been putting in the time, it's going to fall apart. And when it falls apart and you realize it, you still have to put in that same time...A lot of people its ignorance but it's ignorance plus impatience... they just don't want to do the work. And what other problems people come with mental, physiological, spiritual they do not want to do the work. And often that is the biggest problem. They don't want to do the work that it takes. And so, somebody telling me, 'I can only come on Sabbath,' brother...this is not going to work (laughs) It's not going to work period. Ok?

Another element in church life was food. The role of food is central in many social structures. The church provides food for its members called spiritual nourishment. Spiritual nourishment comes from various parts of the church service. When I spoke to one church member, she vividly described how important spiritual nourishment was to her livelihood and times when the spiritual nourishment isn't received in church:

Church member: As a Christian now and my connection to my particular church, or church in general, I think I live a very stressful day-to-day life with my job, with day-to-day chores and family and juggling and doing everything, and I find such peace and calm and joy when it comes to that time of the week when I drop everything, I drop work, I drop all the stresses, I literally drop them, and I focus on worship. It's like a rejuvenating thing for me, I really enjoy going to church, from Sabbath to Sabbath, when I stand up to pray, everything else, all the stresses my joy, family, juggling, and everything else any other pressure that I have, literally just falls to the side, and all I focus on is praising. So, for me it's more for rejuvenating the feel I get when I go to church on Sabbath, on a Saturday morning when I go to church, I do it because, it actually makes me feel rejuvenated and that's the truth.

Researcher: When you said that when you come to church you feel rejuvenated, fresh, what about church helps you feel that way, what in specific?

Church member: I love to sing. I love the sermon that is like the meat and potatoes in the service, but before you get to the meat and potatoes, sometimes you come in and you're tense because of the week that you've had and for me, music is a stress-reliever when there's a song that's being sung and it reaches my soul, music does it for me like $90 \%$ of the time. And like I 
said the meat and potatoes, if I came to church and found that all they were doing is singing that would just not be enough because the meat and potatoes is the sermon so I want to hear the word, I want something that is going to encourage me, something that is going to take me through the week so I need to hear a sermon, I need to hear a word, I need to hear something that is going to encourage me through the week to face the stress that I know I'm going to face Sunday through Friday and dealing with the pressures of my job, dealing with family issues, dealing with just life in general. So, when I come to church and a song, special music, praise and worship, an encouraging word from the pastor, something that's going to make me unwind and distress and encourage me through the week and right off the bat - a song.

Researcher: Has there ever been a time when you came to church and you didn't feel that way? Has that every happened?

Church member: Certainly. Not a lot. But there are times in the past and not necessarily at \#\#\# church where I've been to a church and felt like there wasn't much that I had to grab onto or hold onto. But what I do when I go to the church I honestly try to find one thing, some people don't get it from a sermon, or even from a song, some people might get it from a scripture reading, or I don't know. I try to get it from something...There have been times when I've been to church and didn't feel fulfilled or satisfied that I got enough. And sometimes when there are days or times like that, it was because I didn't prepare myself and didn't do anything through the week, I didn't feel myself through the week so I was spiritually empty so when I got to church, I was looking for someone to fill in the spiritual void that I had not been filling in through the week, so when I went to church looking for someone to fill me, they couldn't do it because I was too empty. The thing about going to church on Sabbath and being filled is you have to continually be feeding and nourishing yourself, you can't be totally starved and there are times when you're totally starved and you go and get filled but if you're totally, totally starved and there's nothing inside and you're empty, it's less likely that you're going to be filled when you go, so you have to be feeding yourself. And there are times when I felt like I didn't get much was probably because I wasn't feeding myself or nourishing myself during the week.

Discipleship and hospitality are two concepts that describe the social interaction of the church family. In a church, there is an expectation for members not only to receive nourishment but also to nourish the needs of others. Discipleship is the activity of learning how to nourish others and nourishing others is referred to as hospitality. Both these concepts puts church members in an active role to reciprocate with others what they've received from leaders. Here is an example of discipleship in a men's ministry:

Elder: You would have men cry cause they shared their problems and they were overwhelmed by the emotional impact it was having on their lives and sharing. And so, we have a very strong men's ministry program. Very strong. We have a retreat we go to each year, over a hundred guys they show up, we normally go there to Virginia Beach and it is very, very helpful. Again, we don't spend time whining, we were just sharing what is the victory because...these meetings can easily turn into a complaint session or grievance session...so, men speak openly, 'I'm into pornography, I know it's a problem, I need help' And so people pray for folk. So, it's real problems that folk are dealing with ...in the church...

The place where discipleship and hospitality take place is within smaller groups called ministries. In my interviews, I discovered that different ministries were all similar in the purpose of discipleship and hospitality.

The church member whom I spoke to in the interview extract below was very active in several ministries and explained why involvement and the nourishing of others, hospitality, is important:

Church member: I've been involved in church ministry since I was 13 till now, and I'm no longer 13 I'm much, much way past that, I have been involved in every aspect of the church...So, I was an Interest Coordinator, I was a Sabbath school secretary, I was a church clerk, and in every role, I've played in church, and I've done other roles, the most, the role that really, I've been consistent in every church that I've ever been to, is singing. I sing on the choir, I sing on the praise team, and I've always done that because it's something that I love to do.

Researcher: So obviously, this is unpaid, this is completely voluntary, what has motivated you to be so active in church?

Church member: To me it's a way of giving back to God just, it's not giving back to God, it's a way of giving to the community, a way of serving. I see myself when I'm greeting at the doors on Sabbath mornings as doing a service for my church for myself actually, because it makes me feel good, it makes me feel like I'm giving back and doing something and doing a service to God. It feels like I'm thanking him as I'm serving whatever capacity it makes me feel like I'm doing it, not to man, but to God. My motivation is just a way of giving something back, my thanks for everything that God has done for me, so when I sing when I'm in the music ministry or greeting ministry or whatever department that I serve in, it's just a way of just giving back, a small way of giving back and saying thank you and playing some kind of role, service, to the church and to God.

There is a special individual in the church who mastered the art of hospitality and modeled the standard of 
hospitality for the church family. Referred to as the 'church mother', this de facto leader used her personality and skills to cater to a variety of needs in the church. The individual is usually an older female who is very influential in the life of the church. I did not have the opportunity to interview a church mother, I assumed that her identity was somewhat concealed; however I talked to an individual who was greatly influenced by her.

My church mom she sings on my choir and she's just the motherly type...I joined the choir because I love to sing and when I joined the choir there was a lady in the choir, my church mom like I said she's like everyone's church mom probably, but she was very caring, she would be very concerned, she would pray, she would send me texts in the morning, worship and devotional texts in the morning and she would just pray for me and asking how I was doing and how is my family...she made me feel very welcome, she prayed for me, my family, my children... when she said she was going to pray for you she was really going to pray for you and that's how it started, she was praying for me. And I realized that when she would call me and she would pray for me, and she continued to pray for me, and it turned to be a relationship where she would send me devotionals, she started praying...I just call her my church mom and I'm sure other people do, she's just a caring woman. But I don't want you to think she came and found me, I actually found her in the choir.

In the next section, I offer an interpretation of the interviewee accounts through the theoretical lens of social support in the church community.

\section{Our family portrait}

The mission statement of the church I attend has the motto We are a family of believers. The first six words shouldn't be taken at face value. The first two words we are represent identity, the next two words a family describes the peculiarity of the community, and the last two words of believers is what unifies, the beliefs and doctrines held by individuals. Who we are and what we believe are crucial to what we think about family and church. To unpack my findings, I discussed the data under the metaphor of a family. The family metaphor describes the hierarchical structure of the church organization, and the church's role to provide various resources of social support, serving as the individual's center of life.

The use of metaphor plays an integral role in research. For one, most of our conceptual system is metaphorical in nature as we use metaphors to structure how we perceive, how we think, and what we do; human thought processes are largely metaphorically structured and defined. ${ }^{21}$ Secondly, the use of metaphors, specifically ontological metaphors, allows us to comprehend a life variety of experiences with nonhuman entities in terms of human motivations, characteristics, and activities. ${ }^{21}$ When researchers dialogue about religion, spirituality and church, these conversations can become convoluted. Therefore, the use of personification, seeing something nonhuman as human, allows for us to make sense of phenomena in human terms, giving us explanatory power. ${ }^{21}$ Finally, the use of metaphors allows researchers to focus on one aspect of a concept and keep away from other aspects that are inconsistent. ${ }^{21}$ Especially in research, it is easy to lose sight of the scope of a concept and all the related entities that it influences and affects; the use of metaphors prevents this unproductive impasse. It is for these reasons that I chose to use the metaphor of a family as a lens to research the church: to focus, explain concepts and processes, and address specific areas of inquiry.

What can we understand about the church by comparing it to a family? One, we are able to conceptualize the social and organizational structures and dynamics involved in church life. Two, we can better understand the interpersonal relationships, social and emotional natures, that form the core of church life. Three, we can accept both positive and negative findings about the church. Because family life is messy, we accept that church life is messy; therefore, we can interpret individual cases in the context of larger outcomes of the social wellbeing of church members. Our expectations are better realigned with the social reality experienced in the church community.

The theory of social support explains the social interaction of church life. A social group is defined as two or more individuals who share a common social identification of themselves, perceiving themselves to be members of the same social category. ${ }^{22}$ This definition stresses that members of a social group seem often to share no more than a collective perception of their own social unity and this seems to be sufficient for them to act as a group. ${ }^{22}$ The group is formed by psychological interdependence; satisfaction of needs, attainment of goals, or consensual validation of attitudes and values. This interdependence leads to cooperative social interaction, communication and mutual influence between individuals. ${ }^{22}$ The church fits the description of a social group such as a family.

The commonplace definition of social support is the availability of psychological, material, and social resources from close relations such as family and friends. ${ }^{14}$ More specifically, social support is information leading a person to believe that he or she is cared for and loved, esteemed, and valued, and that he or she belongs to a network of communication and mutual obligation. ${ }^{23}$ The extension of these definitions can be placed on the recipient of social support, as the extent to which an individual believes that his or his needs for support, information and feedback are fulfilled. ${ }^{24}$ Another way to understand social support is in terms of social networks by studying the various aspects associated with the support network; the social ties to other individuals, groups, and larger community. ${ }^{25,26}$ Recent research and theoretical perspectives have broadened the use of the term to encompass abstract ideas of anticipation, perceptions, 
quality of support, quantity of supportive interactions and other abstract characteristics of persons, behaviors, relationships, or social systems. ${ }^{25}$ The diversity of our understanding of social support can be categorized into: i) kinds: emotional $v s$ instrumental; ii) sources: family $v s$ friends and; iii) other facets, forms or expressions of support. ${ }^{27}$

This research project encompassed the diverse conceptualizations of social support without losing focus of the stated areas of inquiry. The data emphasized the definition of social support using the metaphor of family. Using the metaphor of family, social support was investigated through the established social, organizational networks of the church community, which comprised of social gatherings, small groups and participation in nourishment of others, discipleship and hospitality. These social activities existed in the context of the church to provide social support to large congregations and cater to diverse emotional, psychological and social needs and wellbeing of those in the church community. I argue that the interview accounts reaffirmed how social support is the social exchange of various support resources between church members and leaders, and most importantly the outcome of these exchanges in the expressions of various psychosocial needs and fulfillment of those needs.

The church is a family and this is what social support means in the church community. Using this metaphor, three conclusions can be made. First, the social, organizational structure of the church most resembles a family where the parent assumes authority and decision-making over the larger whole, taking responsibility of the wellbeing of others. Leadership in a family-type of organization ensures accountability and may suggest how power and decision-making can be negotiated to suit the needs of the whole. Secondly, the social, organizational structure of a family describes how social support is distributed to members and overseen by church leaders - the processes and networks of social support within the community. This hierarchical structure in a church family enables various resources of social support to be disseminated over a large population, supported by policies that are intergenerational that ensure the survival of core values. Lastly, the family unit is the center of life for an individual, a concept that represents a resource-center where individuals receive various types of psychosocial needs. In a church, individuals rely on each other for support such as advice, business-professional referrals, dating and friendships; and other emotional needs such as prayer, comforting and socializing. Church life and social support is as diverse as the needs, culture and characteristics of a church community.

\section{Wolves in sheep's clothing and other unnoticeable research challenges}

There were challenges I encountered when conducting this study. First, the recruitment of participants was tedious, partly because of my recruitment strategy. Initially I had planned to find participants on worship days and interview them right after the church service, this did not work. All the participants I found at church during worship were eager to return home and spend time with their families; I did not recognize this at the time. So, I reengineered my efforts by setting up appointments and interview calls during weekdays. The second challenge I encountered was interviewing church leaders. Those who did not know me as well, one participant, was hesitant and skeptical about my study even though I was clear about the consent form and research goals. It is plausible that I may have appeared to be a threat from higher organizational power or someone who could undermine the status quo: however, I cannot validate these assumptions. What I do know now is the importance of developing relationships to release any tension or anxiety with participants. Finally, my research goal changed in the process of conducting this research. Initially I was interested in the church as a source of coping with and improving overall mental health as the review of literature suggested. All but one of my participants did not recognize mental health as a critical issue in the church, yet all participants alluded to various types of psychosocial benefits. It may be that the terminology is not widely used in the church community, yet the concept is identified in other terms. The participants were aware of individuals in the church going through mental health issues but couldn't conclude or connect the church as a coping mechanism. Therefore, my study cannot be used to corroborate literature on coping and religious involvement. This study can only broaden our understanding of social support in a religious community. This discussion provided a baseline for future inquiry.

\section{Conclusions}

From this study, we get a sense of what social support means in one church. What we need to know is whether this is true for other churches, across denominations, and whether there are any generalizable claims about the Christian faith. This study is a call to encourage other researchers to dig deep and wide into the field of Spiritual Communication. Recently, the National Communication Association created a Spiritual Communication division and there is need for it to mature into a robust field connecting with other applied fields such as Health Communication. Practically, the findings of this data were reflexive. Many of the participants I talked to were curious about my findings to know the state of affairs in their church community. One of the participants suggested that the conclusions of this study should be used to create better ministries and provide trainings for church leaders. These are valuable and positive suggestions. Approaching the issues raised in this study require an informed approach to help strengthen the existing social bonds and networks in the faith community.

We are a family of believers is what defines the church. In this study, I referred to the core of family life to dis- 
cover a new frontier in the intersection of religious life and social support. I invite you, my academic community, to join me in this quest across the multicolored landscapes of religious communities. Religious people are happier and healthier because they've got each other, but you've got to see it to believe it.

\section{References}

1. Koenig HG. Research on religion, spirituality, and mental health: a review. Can J Psychiatry 2009;54:283-91.

2. Salsman JM, Pustejovsky JE, Jim HSL, et al. A meta-analytic approach to examining the correlation between religion/spirituality and mental health in cancer. Cancer 2015;121:3769-78.

3. Park CL. Religion as a meaning-making framework in coping with life stress. J Soc Issues 2005;61:707-29.

4. Holt CL, Clark EM, Wang MQ, et al. The religion-health connection among African Americans: what is the role of social capital? J Commun Appl Soc Psychol 2015;25:1-18.

5. Holt C, Wang M, Caplan L, et al. Role of religious involvement and spirituality in functioning among African Americans with cancer: testing a mediational model. J Behav Med 2011;34:437-48.

6. Holt CL, Wang MQ, Clark EM, et al. Religious involvement and physical and emotional functioning among African Americans: the mediating role of religious support. Psychol Health 2013;28:267-83.

7. Brown DR, Gary LE. Religious involvement and health status among African-American males. J Natl Med Assoc 1994;86:825-31.

8. Gupta S, Avasthi A, Kumar S. Relationship between religiosity and psychopathology in patients with depression. Indian J Psychiatry 2011;53:330-5.

9. Ellison CG, Levin JS. The religion-health connection: evidence, theory, and future directions. Health Educ Behav 1998;25:700-20.

10. Levin JS, Markides KS, Ray LA. Religious attendance and psychological well-being in Mexican Americans: a panel analysis of three-generations data. Gerontologist 1996;36: 454-63.

11. Ellison CG, Levin JS, Taylor RJ, Chatters LM. Religious involvement and psychological distress in a national panel study of African Americans, presented at Society for the scientific study of religion and the Religious research association, San Diego; 1997.

12. Blazer D. Religion/spirituality and depression: what can we learn from empirical studies? Am J Psychiatry 2012;169:10-2.

13. Holt C, Roth D, Clark E, Debnam K. Positive self-perceptions as a mediator of religious involvement and health behaviors in a national sample of African Americans. J Behav Med 2014;37:102-12.

14. Cohen S, Wills TA. Stress, social support, and the buffering hypothesis. Psychol Bull 1985;98:310-57.

15. Kluckhohn C. Mirror for man: anthropology and modern life. New York, NY: McGraw-Hill; 1949.

16. Cresswell J. Qualitative inquiry and research design. Thousand Oaks, CA: Sage; 2012.

17. Carbaugh D. The ethnography of communication. In: Donsbach W, ed. The international encyclopedia of communication. Malden, MA: Blackwell; 2008.

18. Neuman, WL. Social research methods: qualitative and quantitative approaches. Needham Heights, MA: Allyn \& Bacon; 1997.

19. Lindlof T, Taylor B. Qualitative communication research methods. Thousand Oaks, CA: Sage; 2011.

20. Charmaz K. Constructing grounded theory: a practical guide through qualitative analysis. Thousand Oaks, CA: Sage; 2006.

21. Lakoff G, Johnson M. Metaphors we live by. Chicago: University of Chicago Press; 1980.

22. Tajfel H. Social identity and intergroup relations. Cambridge University Press; 2010.

23. Cobb S. Social support as a moderator of life stress. Psychosomatic Med 1976;38:300-13.

24. Procidano ME, Heller K. Measures of perceived social support from friends and from family: three validation studies. Am J Commun Psychol 1983;11:1-24.

25. Hupcey JE. Clarifying the social support theory-research linkage. J Adv Nurs 1998;27:1231-41.

26. Lin N, Simeone RS, Ensel WM, Kuo W. Social support, stressful life events, and illness: a model and an empirical test. J Health Soc Behav 1979;20:108-19.

27. Veiel HO, Baumann U. The many meanings of social support. In: Veiel HO, Baumann U, eds. The meaning and measurement of social support. New York, NY: Hemisphere; 1992. 